\title{
Occupational and Environmental Medicine
}

Environmental medicine has become a controversial issue amongst occupational physicians, and the Faculty of Occupational Medicine of the Royal College of Physicians has issued a report in the wake of the American and Australian Colleges adopting Occupational and Environmental Medicine in their titles. $^{1}$

But what debate, if any, is needed when most industry now puts health, safety, and environment under the same management structure and academic units also covet environment in their titles? Unfortunately, the term environmental medicine lends itself to various interpretations. Business may see environmental concerns as the potentially deleterious health, social, and ecological impacts of industrial activity, and occupational physicians as responsible for advising on the aspects relating to human health. Company policy issues may also arise from the global impacts of technological change on energy or climate, for example. But environmental medicine is also about the application of medical sciences for the study, interpretation, and provision of medical advice on the interaction between external physical, chemical, and biological factors and human health. ${ }^{1}$ The health risks under this definition, such as those arising from smoking, diet, and other lifestyle factors, or indirect links between poverty and health, embrace a wider range of medical and non-medical specialties than occupational medicine alone. What needs to be resolved is how the widening role of occupational medicine can be developed and at the same time integrated into the environmental activities of health workers such as epidemiologists, public health physicians, family practitioners, and hospital clinicians.

A new initiative in environmental medicine is overdue with the changes in world technologies over the last two decades. In the United Kingdom, the influence of the medical profession on environmental issues has been weak, although the British Medical Association has entered the fray with reports on pesticides, ${ }^{2}$ hazardous waste, ${ }^{3}$ and the environmental and occupational risks of health care. ${ }^{4}$ Compared with other major employers, however, the NHS has failed to lead in the environmental auditing of its activities, with health care workers so far showing little interest in the environmental impacts of their industry. Assessing the public health risks of exposure to low levels of pollutants is not a requirement of the curriculum in the training of public health or occupational physicians, and the vast majority would be ill equipped to comment on growing public and media concerns on environmental topics such as air pollution from traffic fumes and the implications of the health hazards for a national policy on sustainable transport. The moves to set air quality standards for the United Kingdom highlight the deficiencies in knowledge that exist on the environmental causes for the rising incidence of asthma ${ }^{5}$ and the hazards of genotoxic carcinogens such as benzene. ${ }^{6}$ Remarkably little research effort has been expended on the health effects of outdoor air pollution in the United Kingdom over the last 20 years.

Environmental risk assessments in organisations are undertaken by multidisciplinary teams, and to interact with their non-medical colleagues occupational physicians need to have a working knowledge of a wide range of subjects including atmospheric chemistry, toxic emissions and wastes, eco-toxicology and how to do life cycle product analyses. In the prevention of chemical or other technological accidents the role of human factors remains poorly understood. Disaster planning to comply with the Control of Major Industrial Accident Hazards Regulations 1984 (CIMAH) $^{7}$ has in the past left physicians of most chemical companies on the sidelines when they should be an integral part of the planning and management process and key communicators on risk to the local community. The role of the health care sector in such planning has only been belatedly recognised by international bodies, ${ }^{8}$ showing that the neglect of this role is an international and not only a United Kingdom concern.

Epidemiology is an essential tool in environmental medicine for chronic disease surveillance and the investigation of environmental factors in disease causation. One of the chief attractions of occupational medicine is the scope for combining epidemiological and clinical skills. The important clinical role of occupational physicians, ${ }^{9}$ which some have wished to minimise in the past, needs to be expanded to deal adequately with diseases known or suspected of having environmental causes such as indoor air quality, electromagnetic fields, toxic waste, heavy metal pollution and pesticides, ${ }^{1011}$ and to assist in the management of patients by identifying and evaluating exposure to specific causal agents. This essential role still waits to be filled in the NHS. The emergence in the 1980 s of the NHS occupational health services as providers to other industries should broaden the range of clinical referrals, but this role needs to be extended to include clinics for the diagnosis and management of patients with environmental as well as occupational conditions. ${ }^{12}$ Clinical training for this task would need to be to a more advanced level than that required for specialisation at present.

The environmental health impacts of workplace activities have been recognised since before the Industrial Revolution, yet it is only latterly that health has begun to be integrated into sustainable development, ${ }^{13}$ or that the economic benefit of preventive medicine is being considered in global investment strategies. ${ }^{14}$ One of the key outputs of the United Nations Conference on Environment and Development in Rio de Janeiro in 1992 was agenda 21 , a programme of action to move towards sustainable development. In response, the United Kingdom govern- 
ment strategy on sustainable development makes only limited mention of health as a concern at all. ${ }^{15}$ Even in traditionally non-polluting industries, such as agriculture, environmental health impacts, with their associated costs, can be readily discerned and yet may still be ignored by policy makers. ${ }^{16}$ In the past economists and environmentalists viewed morbidity and mortality as too difficult or too inconvenient to value but health should be an explicit part of environmental and social impact assessments. Occupational health is the one medical specialty which is knowledgeable on risk assessment, and health and safety management, and whose expertise is readily transferable to environmental hazards.

Evidence for the continuing separation of occupational and environmental medicine in the United Kingdom is seen in the division of responsibilities for these areas under three main government bodies-the Health and Safety Executive, the Department of Health, and the Department of the Environment. Even when the Health and Safety Executive was established in the early 1970s the environmental health implications of radiation, asbestos, and vinyl chloride, as well as numerous other hazardous agents in the workplace, were obvious, but the responsibility for the health of the community remained with other bodies. A clear focus for environmental medicine has not developed in government or in universities and their medical schools, nor indeed in the Royal College of Physicians, where the public health physicians and the occupational physicians went separate ways to set up their own Faculties in the 1970s.

With this background and with the need to make radical changes in practice and training, it may seem unduly optimistic or even rash to suppose that a realignment of environmental medicine is in the offing. Yet few would wish to dissuade the Faculty of Occupational Medicine from urgently pursuing an initiative both inside and outside the Royal College of Physicians. Over the last decade a revolution has been taking place in the way organisa- tions do business and in the way they are structured, whereas at the same time the importance of environmental health issues to industry has grown rapidly. For occupational medicine to redefine its role outside the workplace, however, it will need to widen its influence and find a broader vision than the one that has dominated and constrained the thinking of government, industry, and the medical profession up to the present time.

Department of Community Medicine

University of Cambridge Clinical School,

Addenbrooke's Hospital,

Hills Road,

Cambridge CB2 $2 Q Q$

1 Faculty of Occupational Medicine. Report on the Faculty of Occupational Medicine's Working Party on Environmental Medicine. London: Royal Medicine's Working Party on

British Medical Association. Pesticides, chemicals, and health. London: Edward Arnold, 1990.

3 British Medical Association. Hazardous waste and human health. Oxford: Oxford University Press, 1991.

4 British Medical Association. Environmental and occupational risks of health care. London: BMA, 1994.

5 Seaton A, Godden DJ, Brown $\mathrm{K}$. Increase in asthma: a more toxic environment or a more susceptible population? Thorax 1994;49:171-4.

6 Department of the Environment, Expert Panel on Air Quality Standards. Benzene. London: HMSO, 1994.

7 Health and Safety Executive. The control of major industrial accident hazard regulations 1984 (CIMAH): further guidance on emergency plans. London: regulations 1984.

8 Organisation for Economic Cooperation and Development. OECD environment monograph No 81 on health aspects of chemical accidents. Paris: OECD, 1994

9 Seaton A. Occupational medicine-let's keep our white coats and stethoscopes. Occup Med 1993;43:63-4.

10 Ducatman AM, Chase KH, Farid I, et al. What is environmental medicine? $f$ Occup Med 1990;32:1 130-1.

11 Rosenstock L, Rest KM, Benson JA, et al. Occupational and environmental medicine: meeting the growing need for clinical services. $N$ Engl $f$ Med 1991;325:924-7.

12 Raffle PAB, Adams PH, Baxter PJ, Lee WR, eds. Hunter's diseases of occupations, 8th ed. London: Edward Arnold, 1994.

13 World Health Organization. Our planet, our health. Geneva: WHO, 1992.

14 World development report 1993. Investing in health. Washington, DC: World Bank, 1993.

15 Department of Environment. Sustainable development: the UK strategy. HMSO: London, 1994.

16 Baxter PJ. Health and safety on the farm. BMf 1992;305:6-7. 